\title{
Modeling of flow uniformity by installing inlet distributor within the inflow part of a pressurized module using computational fluid dynamics
}

\author{
Changkyoo Choi ${ }^{1}$, Chulmin $\mathrm{Le}^{2}$, In S. $\mathrm{Kim}^{2+}$ \\ ${ }^{1}$ Water Convergence Research Team, Dept. of Water Industry Promotion, Korea Water Cluster, Korea Environment Corporation, Republic of Korea \\ ${ }^{2}$ Global Desalination Research Center (GDRC), School of Earth Sciences and Environmental Engineering, Gwangju Institute of Science and Technology \\ (GIST), Republic of Korea
}

\begin{abstract}
Uniform flow distribution is a significant parameter for designing pressurized membrane modules because non-uniform flow distribution can cause serious local flux and fouling problems within a module. Thus, this study investigated the fluid behavior with regards to the evenness of water distribution using newly designed inlet distributors in the inflow part of a pressurized membrane module. From the results of velocity and pressure at the cross-sectional and outlet planes, we confirmed that a conventional membrane module with no distributor (non-distributor) had fluid that was concentrated at the central part. Case 1, which had a cross-shaped distributor, reduced the central concentration tendency, and Case 2, which had a round-shaped distributor, displayed a relatively uniform flow based on the velocity, pressure, flux, and standard deviation data. Here, the non-uniformity coefficient $(N)$ and energy utilization $(\eta)$ for Cases 1 and 2 showed a lower non-uniformity coefficient ( 0.030 and 0.017 , respectively) than for the Non-distributor (0.039). The energy utilization of Cases 1 and 2 were higher (1.35e-0.5 and 1.46e-05) than the Non-distributor (1.64e-05). Overall, we confirmed that the inlet distributors led to increased evenness of flow distribution within an inflow part.
\end{abstract}

Keywords: Computational fluid dynamics, Energy utilization, Flow distribution, Flux, Non-uniformity coefficient, Pressurized module design

\section{Introduction}

A uniform flow distribution is generally considered an important issue when designing modules, systems, and devices in which fluid flows in membrane modules and reactors [1]. Common industrial modules and devices in water treatment systems, which require a uniform flow distribution, include hollow fiber membrane modules [2-4], membrane distillation [5], spacer-filled channels of spiral-wound membranes [6], spacer-filled disk-type membrane modules [7], pressurized sand filters [8], and fuel cells [1]. A uniform flow distribution within modules often has further advantages in improving the mass transfer, controlling the temperature, and decreasing the pressure loss.

Pressurized membrane modules have a variety of applications in drinking and wastewater treatment systems. However, the performances of pressurized membrane modules are limited by concen- tration polarization and membrane fouling, which causes a flux reduction in the membrane module. In particular, local fouling causes the most serious problems, which include not only a deterioration of the membrane performance but also a reduction in the replacement cycle. Consequently, fouling reduces the economic efficiency and limits the field applicability of pressurized membrane modules [9].

In a pressurized membrane module, geometric properties can also obstruct the flow uniformity and incur abnormal performance of the module. The non-even flow distribution originates from geometrical differences of the module configuration, which include the diameter, shell void fraction, and external manifold of the module [10, 11]. Among these factors, research into the effects of flow distribution on the external manifold have yet to be comprehensively studied [9]. Despite the importance of the external manifold, research has not been conducted for the following reasons. First, the module configuration has been designed by manufacturers

Received June 10, 2019 Accepted January 06, 2020

${ }^{\dagger}$ Corresponding author

Email: iskim@gist.ac.kr

Tel: ++82-62-715-2580 Fax: ++82-62-715-2584

Orchid: 0000-0002-6016-5267

Copyright (C) 2020 Korean Society of Environmental Engineers 
for commercial use in the industry [12]. Second, research cannot accurately analyze the flow parameters and mass transfer when using an actual module, especially as to whether the specific module configuration affects the flow distribution.

To overcome these difficulties, computational fluid dynamics (CFD) is commonly used. Emerging CFD methods can be proposed as an alternative technique for interpreting the effect on module structures. The key benefit of CFD is that it can derive an optimal design by describing the flow patterns of specific configurations of the module, regardless of the expensive cost of a standard mockup test.

In a previous study, Zhuang et al. [13] analyzed the flux distribution in a dead-end outside-in hollow fiber membrane module (HFMM) using a CFD technique, and employed a non-uniformity coefficient and energy utilization to characterize the flux distribution. As a result, they found that a length shorter than $2,000 \mathrm{~mm}$, a shell void fraction larger than 0.4 , and an internal diameter wider than $0.4 \mathrm{~mm}$ were recommended parameters for designing an HFMM. In a more recent study, Zhuang et al. [9] investigated the effect of the inlet manifold on the energy consumption and flow distribution when using the developed CFD model. They confirmed that the CFD results were a good agreement with experimental data and the inlet manifold affected the module performance. Lim et al. [2] further revealed several design parameters of HFMM using CFD, including the packing density, fiber length, fiber inner diameter, and the potting thickness as they analyzed the local flux distribution and permeate flowrate. They recommended that a packing density below 50\% and fiber length above $1 \mathrm{~m}$ should be applied to maintain the pressure drop and permeate flowrate. Li et al. [7] studied the fluid flow on a spacer-filled disk-type membrane module, and focused on the effect of geometry on the membrane module, such as the volumetric flow rate, permeate flux and permeation rate. Through this study, they proposed a collection tube size and spacer thickness for the optimal permeate flux. Finally, Wang et al. [14] studied novel liquid distributors that were used to enhance the vacuum membrane distillation (VMD) permeate flux through a three-dimensional CFD simulation. As a result, structural parameters were optimized for uniform liquid distribution, thus confirming that distributors can improve the permeate flux by $5 \%$ for flat-plate distributors and from $6 \%$ to $12 \%$ for pyramidal distributors.

From the literature review, CFD could accurately interpret the flow distribution for novel module designs, i.e., the module configurations, distributors, module shapes, etc. Therefore, using computational fluid dynamics, the purpose of this study is to investigate the fluid behavior due to velocity, pressure, and flux, and explain the evenness of water distribution on the inflow part of a pressurized module required to induce the non-uniformity coefficient and improve energy utilization. The originality of this study is to determine the effect of the uniform fluid distribution using newly designed inlet distributors installed at the inflow part of a pressurized membrane module.

\section{Simulation Set-up}

\subsection{Governing Equations}

In this study, ANSYS CFX (version 18.0) was employed to simulate fluid behaviors such as velocity, pressure, and flux. CFX is the most widely used CFD software tool because of its outstanding accuracy in the hydraulic analysis of membrane modules [15].

The governing equation of ANSYS CFX is the Navier-Stokes equation, which describes conservation and transport processes. For turbulent flow, the K-epsilon $(k-\varepsilon)$ model can analyze flow properties for turbulence conditions in CFD. In this model, there are two variables: turbulence kinetic energy $(k)$ and the rate of dissipation of turbulence energy $(\varepsilon)$. The turbulent viscosity is assumed to be isotropic, as the ratio between the Reynolds stress and deformation rate is the same in all directions [16]. Note that $k-\varepsilon$ equations may have many unknown terms; however, the standard $k-\varepsilon$ model minimizes the unknown factors, and thus can be used in turbulent flow applications. The equations of turbulent kinetic energy $(k)$ and dissipation $(\varepsilon)$ are follows [17].

$$
\begin{gathered}
k: \frac{\partial(\rho k)}{\partial t}+\frac{\partial\left(\rho k u_{i}\right)}{\partial x_{i}}=\frac{\partial}{\partial x_{j}}\left[\frac{\mu_{t}}{\sigma_{k}} \frac{\partial k}{\partial x_{j}}\right]+2 \mu_{t} E_{i j} E_{i j}-\rho \varepsilon \\
\varepsilon: \frac{\partial(\rho \varepsilon)}{\partial t}+\frac{\partial\left(\rho \varepsilon u_{i}\right)}{\partial x_{i}}=\frac{\partial}{\partial x_{j}}\left[\frac{\mu_{t}}{\sigma_{\varepsilon}} \frac{\partial \varepsilon}{\partial x_{j}}\right]+C_{1 \varepsilon} 2 \mu_{t} E_{i j} E_{i j}-C_{2 \varepsilon} \rho \frac{\varepsilon^{2}}{k}
\end{gathered}
$$

where $u_{i}$ is the velocity component in the corresponding direction, $E_{i j}$ is the component of the deformation rate, and $\mu_{t}$ is the eddy viscosity.

The constants $\sigma_{k}, \sigma_{\varepsilon}, C_{1 \varepsilon}$, and $C_{2 \varepsilon}$ are adjustable and have been determined by many iterations for turbulent flow conditions. From previous results, the values of these constants are follows: $C_{\mu}=$ 0.09, $\sigma_{k}=1.00, \sigma_{\varepsilon}=1.30, C_{1 \varepsilon}=1.44$, and $C_{2 \varepsilon}=1.92$ [17].

\subsection{Module Structure}

A pressurized membrane module commonly has inflow, membrane, and outflow parts; in this study, the inflow part was simulated because we need to analyze the characteristics of flow distribution when influent water reaches the membrane through this part. The inflow has a down-to-up flow, where the inlet plane is the lower section and the outlet plane is the upper section, as shown in Fig. 1. The outlet plane was divided into nine sections in order to analyze the flux distribution. Table 1 presents the module specifications for an effective area and volume of the inlet distributors, which have cross and round shapes to efficiently distribute the

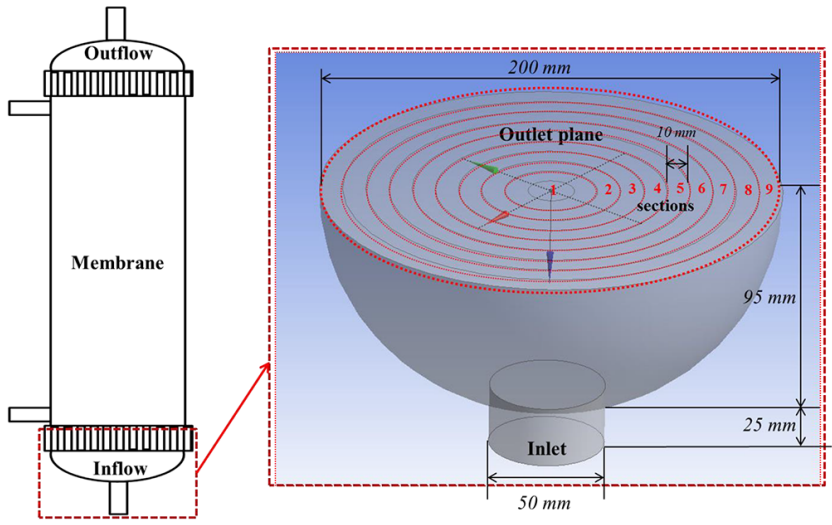

Fig. 1. Structure and specifications of the inflow part. 


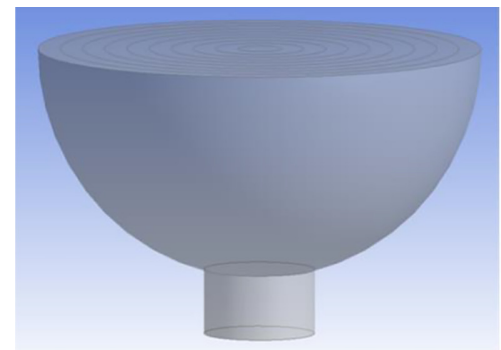

Non-distributor

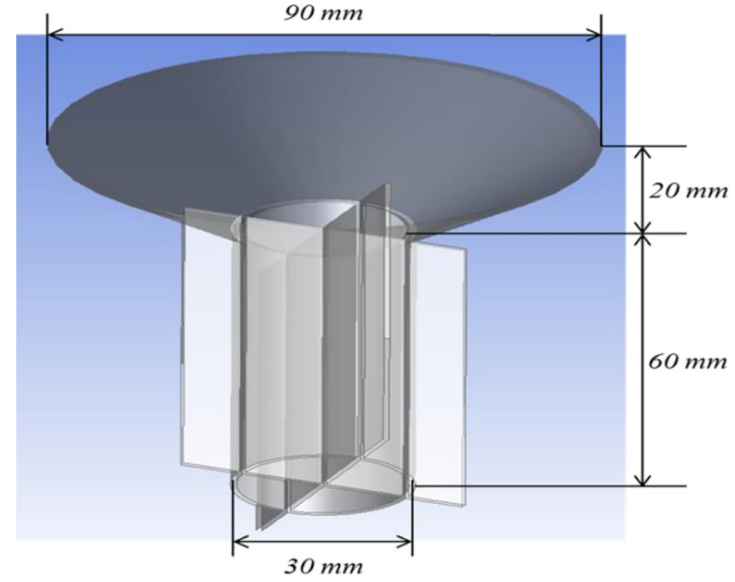

Inlet distributor (Case 1)

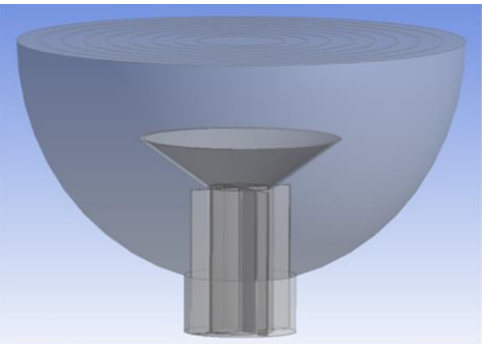

Inlet distributor (Case 1)

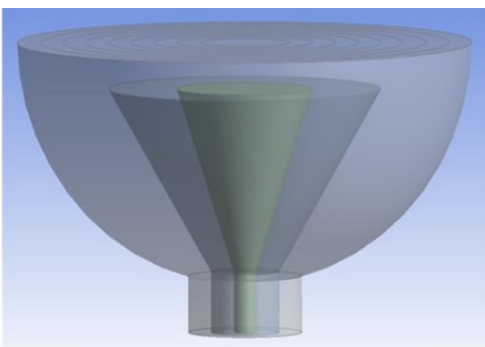

Inlet distributor (Case 2)

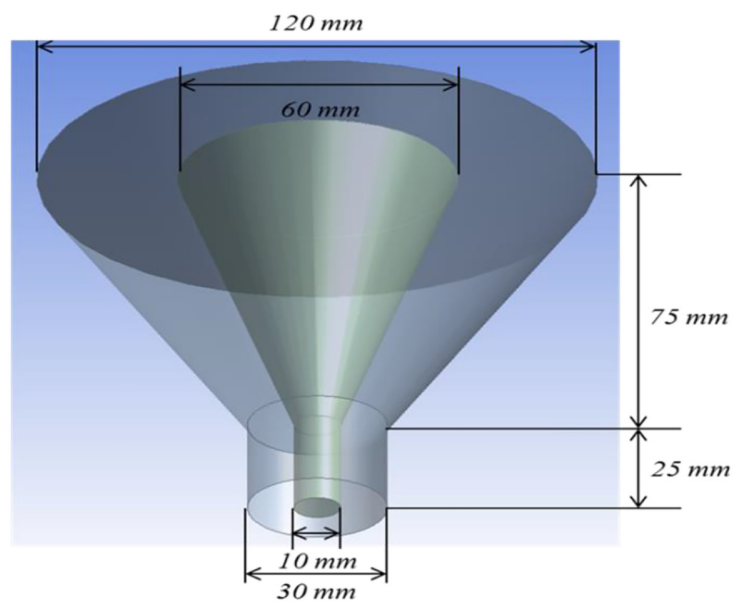

Inlet distributor (Case 2)

Fig. 2. Detailed specifications of the inlet distributors.

Table 1. Module Specification of Effective Area and Volume on Inlet Distributors

\begin{tabular}{lccc}
\hline Conditions & Items & Inlet & Outlet \\
\hline \multirow{2}{*}{ Non-distributor } & Area $\left(\mathrm{cm}^{2}\right)$ & 19.5 & \multicolumn{2}{c}{361.4} \\
& Volume $\left(\mathrm{cm}^{3}\right)$ & \multicolumn{2}{c}{2,140} \\
\hline \multirow{2}{*}{ Case 1 } & Area $\left(\mathrm{cm}^{2}\right)$ & 17.7 & \multicolumn{2}{c}{361.4} \\
& Volume $\left(\mathrm{cm}^{3}\right)$ & \multicolumn{2}{c}{2,086} \\
\multirow{2}{*}{ Case 2 } & Area $\left(\mathrm{cm}^{2}\right)$ & 19.5 & \multicolumn{2}{c}{361.4} \\
& Volume $\left(\mathrm{cm}^{3}\right)$ & \multicolumn{2}{c}{2,136} \\
\hline
\end{tabular}

${ }^{*}$ Non-distributor indicates a conventional membrane module with no distributor.

influent water, then the volume is little different due to the shape of inlet distributors. The detailed specifications of inlet distributors on the module are in Fig. 2.

\subsection{Boundary Conditions}

Simulations in this study were analyzed using three-dimensional flows at turbulent mode. Using CFD, the boundary condition can be set based on the flowrate, pressure, and velocity. In this study, the boundary condition is set as the inlet pressure (100 kPa), a common inlet pressure [18], and the outlet pressure is $0 \mathrm{kPa}$. The fluid temperature is $20^{\circ} \mathrm{C}$ and the wall boundary conditions were applied under non-slip conditions.

\subsection{Non-uniformity Coefficient and Energy Utilization}

The flow distribution is the correlation between the transmembrane pressure distribution and the permeability distribution at a specific location. A non-uniformity coefficient, $N$, that considers the correlation can be estimated from the flux distribution; $N$ is the standard deviation of the local flux, and indicates there is less uniform distribution when it is larger. The non-uniformity coefficient can be calculated from Eq. (3) and (4) [13].

$$
\begin{gathered}
N=\sqrt{\frac{1}{L} \int_{0}^{L}\left(\frac{J}{\hat{\jmath}}-1\right)^{2} d z} \\
\hat{\jmath}=\frac{1}{L} \int_{0}^{L} J d z
\end{gathered}
$$

where $J$ is the flux at the specific location, and $\hat{\jmath}$ is the length-averaged local flux.

A non-even flux distribution causes the non-uniformity of the partial distribution, as well as low energy utilization. Therefore, a parameter of the energy utilization, $\eta$, is the pressure drop in transmembrane pressure for filtration as fluid is transported to the place; $\eta$ can be calculated from Eq. (5) and (6).

$$
\eta=\frac{\int_{0}^{A} J d A}{\int_{0}^{A} J_{l i m} d A}
$$




$$
J_{\text {lim }}=\frac{\left(p_{0}-p_{L}\right)}{\mu R_{m}}
$$

where $p_{0}$ is the pressure at the inlet, $p_{L}$ is the pressure at the specific location, and $J_{\text {lim }}$ is the ratio between the pressure drop and dynamic viscosity.

$\eta$ indicates the energy utilization of a module and can be applied to most pressurized modules regardless of their shapes. Hence, $N$ and $\eta$ are parameters commonly used to verify the effect of a variety of geometrical configurations [13].

Here, $N$ and $\eta$ were derived from five planes, e.g., the inlet, and at $2.8 \mathrm{~cm}, 9.0 \mathrm{~cm}, 11.0 \mathrm{~cm}$, and $12 \mathrm{~cm}$ from inlet, in order to determine the even flow distribution at the inflow part. The locations of the five points measured are shown in Fig. S1.

\section{Results and Discussion}

\subsection{Fluid Dynamics at Inlet and Outlet Plane}

Fig. 3 presents the average velocity and pressure values at the inlet and outlet for the Non-distributor, Case 1, and Case 2. In Fig. 3(a), the inlet velocities for the Non-distributor and Case 2 were $10.873 \mathrm{~m} / \mathrm{s}$ and $11.146 \mathrm{~m} / \mathrm{s}$, respectively, and that of Case 1 was $10.246 \mathrm{~m} / \mathrm{s}$, which is relatively smaller than other conditions. The velocity at the outlet was the largest at $5.024 \mathrm{~m} / \mathrm{s}$ for the Non-distributor, compared to $3.199 \mathrm{~m} / \mathrm{s}$ for Case 1 and $3.130 \mathrm{~m} / \mathrm{s}$ for Case 2.

In Fig. 3(b), the average pressure values at the inlet were about $49.9 \mathrm{kPa}$ under all conditions, and those at the outlet were maintained at $14.0 \mathrm{kPa}$ for the Non-distributor, $5.9 \mathrm{kPa}$ for Case 1, and $5.6 \mathrm{kPa}$ for Case 2. These results confirm that the fluid flows smoothly through the outlet in Cases 1 and 2, though not through the Non-distributor.

The reason that Cases 1 and 2 displayed a low velocity and pressure at the outlet was that the volumes of Cases 1 and 2 were $2086 \mathrm{~cm}^{3}$ and $2136 \mathrm{~cm}^{3}$, whereas the Non-distributor was 2,140 $\mathrm{cm}^{3}$. Hence, it was considered that the inlet distributor greatly divided the inflow part and acted as a large barrier of the fluid flow.

\subsection{Velocity and Pressure at Cross-sectional Plane}

In turbulent flow mode, the CFD results displayed the velocity vector profile in the vertical cross-section (Fig. 4(a)). The intensity of velocity in the contour can be interpreted as follows: red > orange $>$ yellow $>$ green $>$ sky blue $>$ blue. The large amount of red and blue means that the fluid flow is localized; conversely, abundant orange, yellow, green, and sky blue implies that that the flow is evenly distributed.

In Fig. 4(a), the Non-distributor showed that the fluid velocity was concentrated at the central part and the average velocity at the cross-sectional plane at that time was $3.987 \mathrm{~m} / \mathrm{s}$. In Case 1, the tendency to concentrate in the center part was lower and the average velocity increased to $4.623 \mathrm{~m} / \mathrm{s}$ compared to the Non-distributor. The fluid velocity of Case 2 at the cross-sectional plane was relatively uniform, and the average velocity was the highest at $5.501 \mathrm{~m} / \mathrm{s}$ among all conditions, as the fluid velocity is equally distributed in the flow part due to the shape of the inlet distributor, which could divide the fluid into three quarters. The average velocity of Case 2 was higher than that of Case 1, indicating that an ideal fluid flow was observed from among the three conditions. Also, in Case 2, the red color at the center of inlet pipe was due to the fact that the cross-sectional area of the center circle was $78.5 \mathrm{~cm}^{2}$, smaller than the other circles; the area of the $2^{\text {nd }}$ circle was $628 \mathrm{~cm}^{2}$ and the edge circle was $1,256 \mathrm{~cm}^{2}$. Overall, the fluid velocity at the cross-sectional plane in the inflow part was high and displayed the most even distribution in Case 2 , indicating the ideal flow.

The vertical cross-sectional plane of the pressure contour at the inflow part under turbulent mode is shown in Fig. 4(b). For the velocity, the intensity of pressure in the contour can be interpreted as follows: red $>$ orange $>$ yellow $>$ green $>$ sky blue $>$ blue, with red, orange, and yellow indicating that the fluid flow is stagnant at that point and that the water pressure is high. Green, sky blue, and blue indicate that the fluid passes rapidly at that point, and that the water pressure is low.

From the results of Fig. 4(b), the pressure distribution of the Non-distributor was biased toward the center of the cross-sectional plane, and the mean pressure was $17.6 \mathrm{kPa}$. Here, the fluid is concentrated at the center part and is stagnated at the other part, so that a high pressure was maintained entirely in the inflow part. In Case 1, the average pressure was slightly lower at $13.3 \mathrm{kPa}$, as the fluid biasing phenomenon in the central part was reduced compared to the Non-distributor, however, the shape of the inlet distributor was a funnel and so the fluid partially stagnated in the module, resulting in dead space ( 4 blue spots). The water pres-
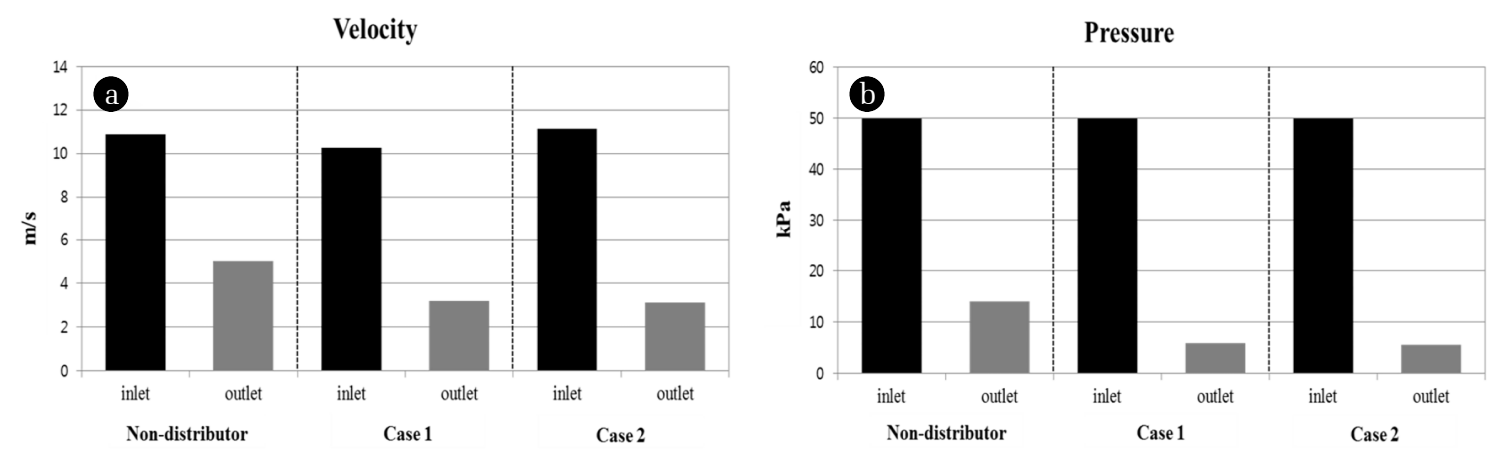

Fig. 3. (a) Average velocity and (b) Pressure values at the inlet and outlet for the inlet distributors. 


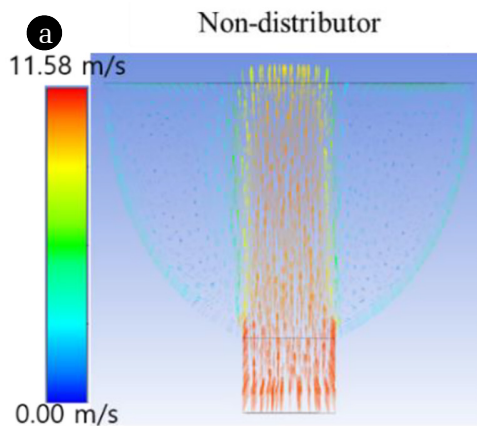

b

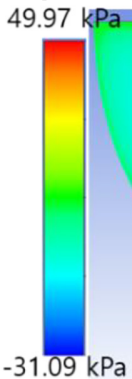

Non-distributor

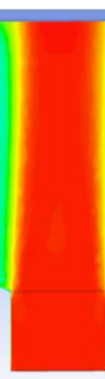

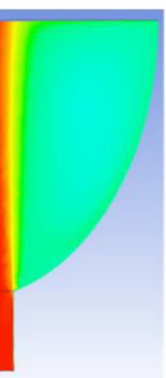

Case 1

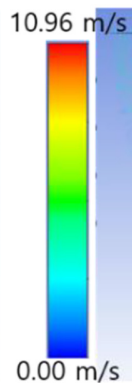

$0.00 \mathrm{~m} / \mathrm{s}$

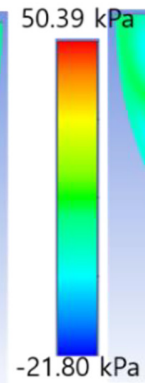

Case 1
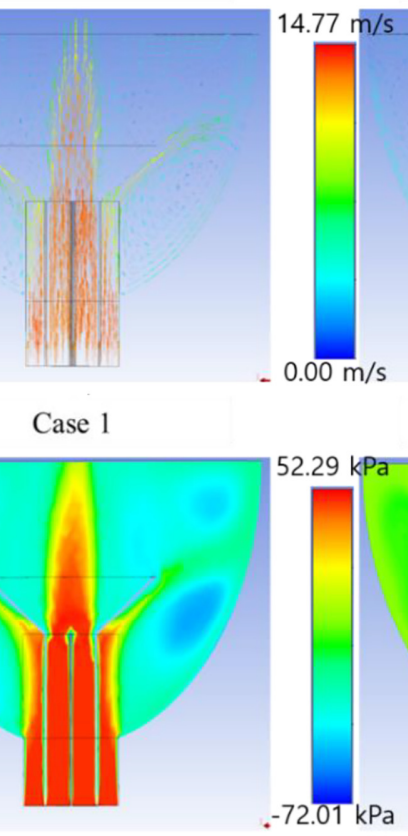

Case 2

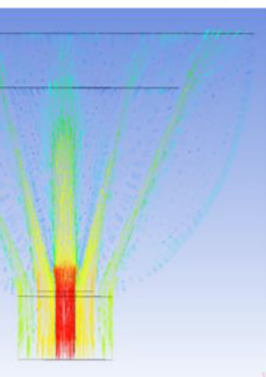

Case 2

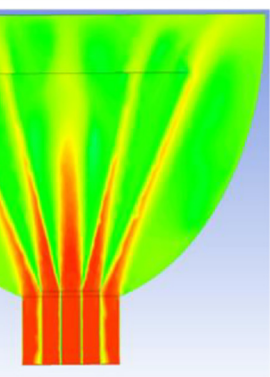

Fig. 4. Contour images of velocity vector and pressure on inlet distributors at cross-sectional planes: (a) Velocity vector and (b) Pressure.

sure distribution of Case 2 was relatively uniform and the mean pressure value was low at $14.2 \mathrm{kPa}$, because the fluid was evenly distributed by the round-shaped inlet distributor in the inflow part. Overall, the lowest water pressure was observed in the cross-sectional plane having the fastest flow velocity.

From the above results, Case 2 displayed the fluid velocity indicating the ideal fluid flow, as the water pressure at the cross-sectional plane showed the most uniform distribution and lowest water pressure.

\subsection{Fluid Dynamics at Sections on the Outlet}

3.3.1. Velocity and pressure variation at sections on the outlet Fig. 5 displays the average velocity and pressure values at nine sections that divided the outlet plane at $20 \mathrm{~cm}$ interval. From the results of Fig. 5(a), the Non-distributor showed a higher flow velocity range at the outlet plane than the other cases, probably because the inlet distributor was not installed at the inflow part, and as such did not interfere with the fluid flow. In detail, the Non-distributor showed significantly high velocity at Section 1, and Sections 2 to 9 exhibited a nearly constant velocity; the standard deviation was $1.435 \mathrm{~m} / \mathrm{s}$ (maximum $8.603 \mathrm{~m} / \mathrm{s}$ at Section 1 and minimum $3.438 \mathrm{~m} / \mathrm{s}$ at Section 9). Case 1 displayed the highest velocity in Section 1, but the velocity bias at Section 1 steeply decreased compared to the Non-distributor, and the velocities in Sections 2 to 9 were almost constant. The standard deviation in Case 1 was $0.730 \mathrm{~m} / \mathrm{s}$ (max. $4.359 \mathrm{~m} / \mathrm{s}$ at Section 1 and $\min .2 .296 \mathrm{~m} / \mathrm{s}$ at Section 9) indicating the lowest standard deviation for these conditions. Case 2 had higher velocities at Sections 4 to 8 than at Sections 1, 2, 3, and 9. The standard deviation in Case 2 was $0.765 \mathrm{~m} / \mathrm{s}$ (max. $4.161 \mathrm{~m} / \mathrm{s}$ at Section 5 and $\min .1 .888 \mathrm{~m} / \mathrm{s}$ at Section 3), which was similar to that for Case 1.

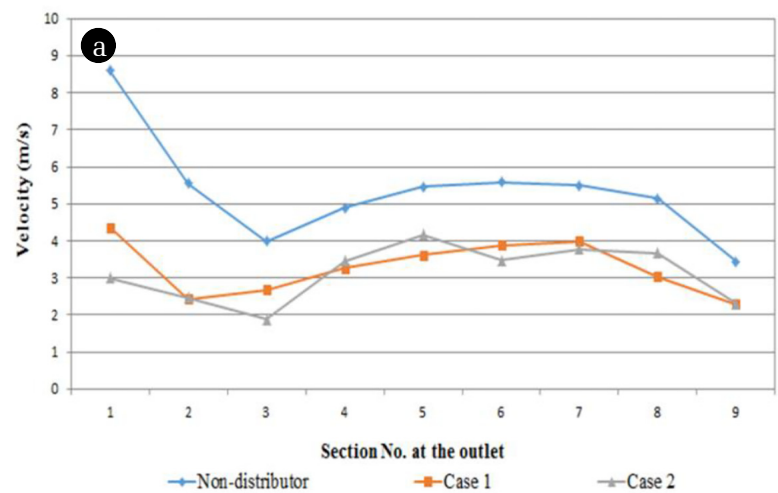

Fig. 5. Average velocity and pressure at sections of the outlet plane:

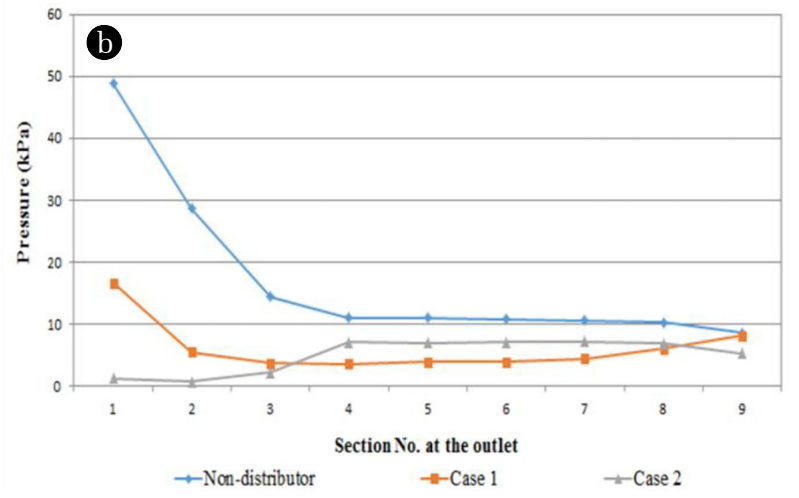

(a) Velocity and (b) Pressure. 
Overall, it can be seen that Cases 1 and 2 have a more constant fluid velocity distribution than for the Non-distributor on the entire outlet plane, as the inlet distributors evenly distribute the fluid velocity from the inlet plane and increase the velocity within the inflow part.

In Fig. 5(b), which presents the average pressure values at nine sections, the Non-distributor and Case 1 showed the highest pressure values at Section 1, but the pressure for Case 1 was low. The Non-distributor showed a significantly higher velocity at Section 1 compared to Case 1, as in Fig. 5(a), indicating that the central concentration phenomenon of the fluid flow was reduced due to the even distribution of the inlet distributor. In addition, Case 2 showed relatively constant pressure values at the outlet plane, in spite of the low pressure values at Sections 1 to 3, because of its most even pressure distribution within an inflow part due to the round-type inlet distributor. In detail, the standard deviation of the pressure values for the Non-distributor was $13 \mathrm{kPa}$ (max. $48.8 \mathrm{kPa}$ at Section 1 and min. $8.5 \mathrm{kPa}$ at Section 9), that of Case 1 was 4 $\mathrm{kPa}$ (max. $16.6 \mathrm{kPa}$ at Section 1 and min. $3.5 \mathrm{kPa}$ at Section 4), and that of Case 2 was $3 \mathrm{kPa}$ (max. $7.2 \mathrm{kPa}$ at Section 7 and min. 0.7 $\mathrm{kPa}$ at Section 2). Thus, in terms of the fluid pressure at the outlet plane, Cases 1 and 2 with inlet distributors resulted in a relatively uniform pressure distribution, rather than for the Non-distributor which had the highest standard deviation in the outlet plane.

\subsubsection{Flux variation at sections on the outlet}

Fig. 6 displays the average flux values in nine sections on the outlet plane, spaced at $10 \mathrm{~cm}$ intervals. From the results, it can be seen that all fluid passed through Sections 1 to 3 in a Non-distributor; there was no flux in other sections. The standard deviation was greatest at 183,652 $\mathrm{L} /\left(\mathrm{m}^{2} \cdot \mathrm{h}\right)\left(\max .505,948 \mathrm{~L} /\left(\mathrm{m}^{2} \cdot \mathrm{h}\right)\right.$ in Section 1, with a minimum of $0 \mathrm{~L} /\left(\mathrm{m}^{2} \cdot \mathrm{h}\right)$ in Sections 4 to 9$)$. In Case 1, all fluid went through Sections 1, 3, 8, and 9, though there was no flux in Sections 4 to 7 because the inlet distributor had a wide funnel shape at the end part, and the fluid did not reach the outlet plane. Here, the standard deviation was $86,945 \mathrm{~L} /\left(\mathrm{m}^{2} \cdot \mathrm{h}\right)$ (max. $263,634 \mathrm{~L} /\left(\mathrm{m}^{2} \cdot \mathrm{h}\right)$ at Section 1 , with a minimum of $0 \mathrm{~L} /\left(\mathrm{m}^{2} \cdot \mathrm{h}\right)$ in Sections 4 to 7); the standard deviation for Case 1 is lower than for the Non-distributor. In Case 2, the fluid passed through all sections of the outlet plane except for Section 2, and the standard deviation was the lowest at $27,599 \mathrm{~L} /\left(\mathrm{m}^{2} \cdot \mathrm{h}\right)\left(\max .83,687 \mathrm{~L} /\left(\mathrm{m}^{2} \cdot \mathrm{h}\right)\right.$ at Section 7 , with a minimum of $0 \mathrm{~L} /\left(\mathrm{m}^{2} \cdot \mathrm{h}\right)$ in Section 2). These results confirm that the fluid is relatively uniformly distributed

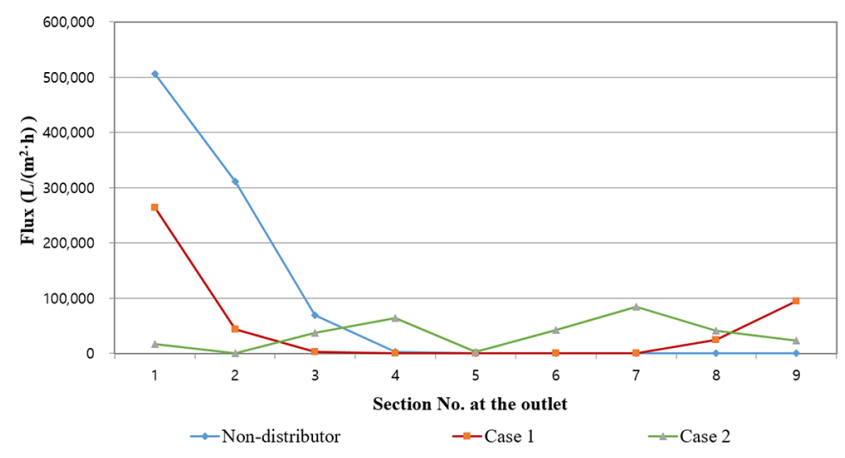

Fig. 6. Flux variations at sections on the outlet plane. in the inflow part in Case 2, as the inlet distributor has two rounded shapes. Overall, the flux distribution in sections of the outlet plane was the best in Case 2, and it had the potential to reduce the local flux and fouling by maintaining an even flux due to the shape of the inlet distributor.

\subsection{Non-uniformity Coefficient and Energy Utilization at Each Plane}

As mentioned in chapter 2.4, the non-uniformity coefficient $N$ is the standard deviation of the local fluxes at the specific plane, which indicated that the evenness of flow is higher when the value is smaller. Fig. 7 presents the values of the non-uniformity coefficient at five planes, i.e., the inlet, and at $2.8 \mathrm{~cm}, 9 \mathrm{~cm}, 11$ $\mathrm{cm}$ and $12 \mathrm{~cm}$ (outlet) from inlet, to identify the evenness of flow within the inflow part.

In Fig. 7(a), the $N$ of the Non-distributor is the largest in all planes, with Cases 1 and 2 being relatively small, proving that the flow was uniform on each plane due to the inlet distributors. In addition, the $N$ at the inlet was the largest compared to other planes, with the $N$ values at $2.8 \mathrm{~cm}, 9 \mathrm{~cm}$, and $11 \mathrm{~cm}$ remaining almost constant; there was only a slight increase at the outlet plane $(12 \mathrm{~cm})$. Here, the fluid flow from the inlet was stabilized as it passed the $2.8 \mathrm{~cm}, 9 \mathrm{~cm}$, and $11 \mathrm{~cm}$ planes, even though the diameter of inflow part increased, and the $N$ at the outlet plane was influenced by the presence or absence of inlet distributors.

In detail, $N$ values at $2.8 \mathrm{~cm}$ for the Non-distributor, Case 1, and Case 2 were 0.023, 0.013, and 0.009, respectively; Cases 1 and 2 were lower compared to the Non-distributor, indicating an even flow distribution at this plane due to the effect of the inlet distributors. $N$ values for Case 2 at $9 \mathrm{~cm}$ and $11 \mathrm{~cm}$ were the lowest at 0.0091 and 0.0088 , respectively, whereas the $N$ values at these planes were 0.015 and 0.014 for the Non-distributor, and 0.016 and 0.012 for Case 1. The total length of the inlet distributor in Case 1 was shorter, at $8 \mathrm{~cm}$, than for Case 2, which reduced its influence. However, the $N$ values at the outlet plane were 0.039 for the Non-distributor, 0.030 for Case 1, and 0.017 for Case 2. Overall, Case 2 displayed the lowest non-uniformity coefficient, and Case 1 was slightly lower than the Non-distributor. These results confirm that the fluid from the inlet was evenly distributed to the outlet plane within the inflow part. Here, the non-uniformity coefficient illustrated the fact that the inlet distributor in Cases 1 and 2 induced an even flow distribution during fluid flow from the inlet to the outlet.

A parameter of the energy utilization, $\eta$, refers to the pressure drop as a fluid is transported to a place; a high $\eta$ denotes a low pressure drop and energy utilization of the module newly designed. Fig. 7(b) shows the values of energy utilization at four planes $(2.8$ $\mathrm{cm}, 9 \mathrm{~cm}, 11 \mathrm{~cm}$, and $12 \mathrm{~cm}$ (outlet)) based on the initial pressure at the inlet.

In Fig. 7(b), based on the initial pressure at the inlet, the $\eta$ at $2.8 \mathrm{~cm}$ was 0.0019 for the Non-distributor, 0.0046 for Case 1, and 0.0033 for Case 2; Case 1 was the highest and the Non-distributor was the lowest. It is posited here that the pressure drop decreased because the flow was evenly distributed by the inlet distributor. The $\eta$ at $9 \mathrm{~cm}, 11 \mathrm{~cm}$, and $12 \mathrm{~cm}$ steeply decreased, as there was a rapid pressure drop compared to $2.8 \mathrm{~cm}$ in all conditions. 

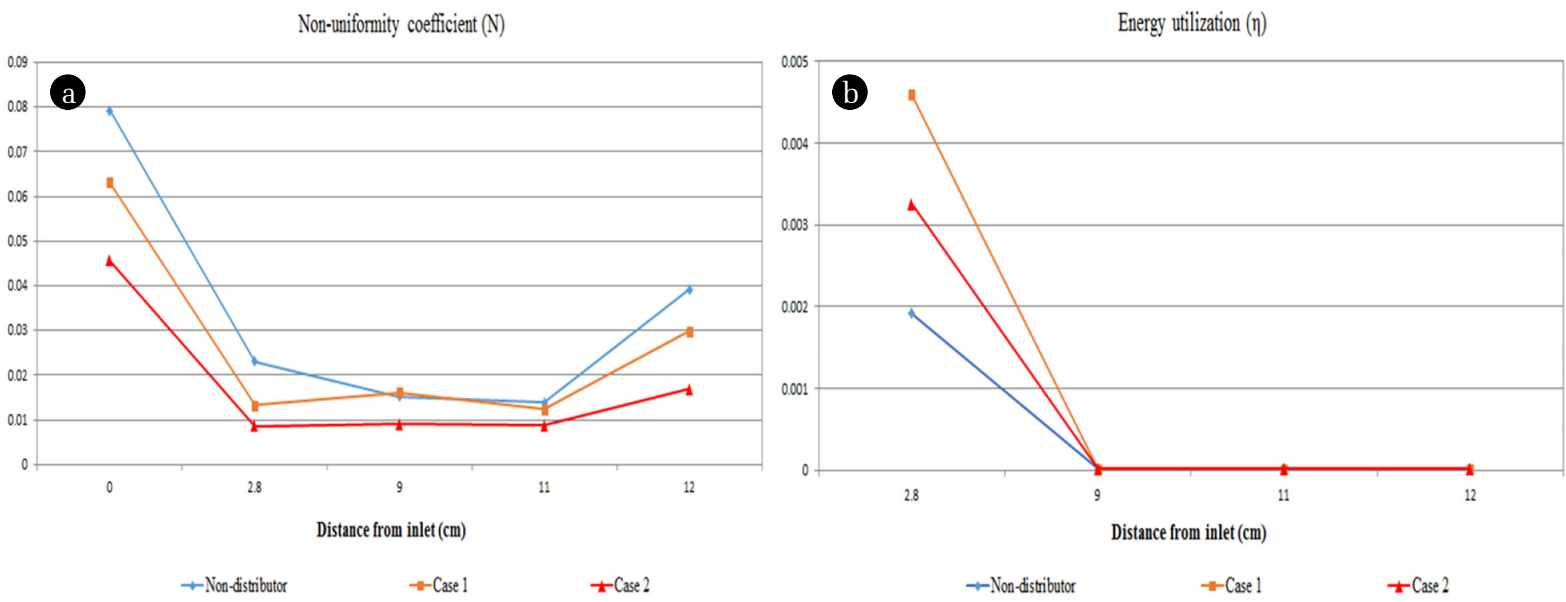

Fig. 7. Non-uniformity coefficients at five planes within the inflow part: (a) Non-uniformity coefficient and (b) Energy utilization.

The $\eta$ values at $12 \mathrm{~cm}$ (outlet plane) were 1.64e-05 for the Non-distributor, 1.35e-0.5 for Case 1, and 1.46e-05 for Case 2; the Non-distributor showed a slightly higher value, with the lowest pressure drop, because the fluid was not disturbed by inlet distributor.

Zhuang et al. [13] reported that there is a low $N$ and high $\eta$ when the shell void fraction $(\varepsilon)$ in the membrane module is large. Under this condition, there is generally a uniform flow and high energy efficiency due to the low pressure drop when the water channel is increased in the membrane module. In our study, Case 2 showed a more uniform flow than Case 1 and the Non-distributor has higher energy efficiency than Case 1 with its complicated configuration. Hence, Case 2 appears to have a more ideal flow pattern.

\section{Conclusions}

The intent of this study is to use CFD to investigate the fluid behavior in terms of evenness of water distribution and to induce the non-uniformity coefficient and energy utilization when inlet distributors are installed at the inflow part of a pressurized module. The results are as follows.

From the results of the average velocity and pressure values at the inlet and outlet of the Non-distributor, Case 1, and Case 2 , the average velocity and pressure at the outlet for the Non-distributor was the largest at $5.024 \mathrm{~m} / \mathrm{s}$ and $14.0 \mathrm{kPa}$, respectively. It was considered that the inlet distributor in Cases 1 and 2 acted as a large barrier of fluid flow due to the smaller effective volume than in the Non-distributor.

In the CFD results of velocity and pressure at the cross-sectional plane, the Non-distributor showed that the fluid velocity was concentrated into the central part, and the fluid velocity of Case 2 was relatively uniform, and the average velocity was the highest at 5.501 $\mathrm{m} / \mathrm{s}$ among all conditions, because of the inlet distributor shape.

In terms of average velocity and pressure at nine sections of the outlet plane, Case 2 had a relatively low standard deviation and a more constant fluid velocity distribution than the Non-distributor on the outlet plane. From the average pressures at these nine sections, Case 2 also showed constant pressure values at the outlet plane, because it had the most even pressure distribution within the inflow part due to it round-type inlet distributor.

In the flux values at the nine sections at the outlet plane, all fluid passed through Sections 1 to 3, and standard deviation was the greatest at $183,652 \mathrm{~L} /\left(\mathrm{m}^{2} \cdot \mathrm{h}\right)$ in the Non-distributor. On the other hand, Case 2 showed that the fluid passed through all sections of the outlet plane except for Section 2, and its standard deviation was the lowest at $27,599 \mathrm{~L} /\left(\mathrm{m}^{2} \cdot \mathrm{h}\right)$, indicating an even flow distribution. Based on these results, Case 2 has the potential to reduce the local flux and fouling due to its round-shaped inlet distributor, which is divided into 3 parts.

The non-uniformity coefficient, $N$, of the Non-distributor was the largest in all planes. As Cases 1 and 2 were smaller, the flow was uniform on each plane due to the inlet distributors. The energy utilization parameter, $\eta$, of Case 1 was the highest and that of the Non-distributor was the lowest. It seems that the pressure drop of Case 1 decreases because the flow is evenly distributed by the inlet distributor.

In summary, the fluid flow induced by the inlet distributor of Case 2 maintained the most even distribution within an inflow part of a pressurized module, based on the parameters of velocity, pressure, flux, non-uniformity coefficient, and energy utilization. As the results, if the inlet distributor is installed in the inflow part of the in-out membrane module, local fouling can be reduced by evenly distributing the fluid flowing into lumen side of membrane.

\section{Acknowledgment}

This work was supported by the Korea Environment Industry \& Technology Institute (KEITI) through the Industrial Facilities \& Infrastructure Research Program, funded by the Korea Ministry of Environment (MOE) (1485016274).

\section{Author Contributions}

C.K.C. (Senior researcher) investigated references, conducted experimental design, and wrote the paper. C.M.L. (Ph.D student) 
simulated the CFD program on the experimental conditions. I.S.K. (Professor) supervised theme, methods and results of the paper.

\section{References}

1. Liu H, Li P, Lew JV. CFD study on flow distribution uniformity in fuel distributors having multiple structural bifurcations of flow channels. Int. J. Hydrog. Energ. 2010;35:9186-9498.

2. Lim KB, Wang PC, An H, Yu SCM. Computational studies for the design parameters of hollow fibre membrane modules. J. Membr. Sci. 2017;529:263-273.

3. Zhuang L, Dai G, Xu ZL. Three-dimensional simulation of the time-dependent fluid flow and fouling behavior in an industrial hollow fiber membrane module. AlChE J. 2018;64:2655-2669.

4. Zhang LZ, Li ZX, Zhong TS, Pei LX. Flow maldistribution and performance deteriorations in a cross-flow hollow fiber membrane module for air humidification. J. Membr. Sci. 2013;427:1-9.

5. Soukane S, Naceur MW, Francis L, Alasaadi A, Ghaffour N. Effect of feed flow pattern on the distribution of permeate fluxes in desalination by direct contact membrane distillation. Desalination 2017;418:43-59.

6. Bucs SS, Linares RV, Marston JO, Radu AI, Vrouwenvelder JS, Picioreanu C. Experimental and numerical characterization of the water flow in spacer-filled channels of spiral-wound membranes. Water Res. 2015;87:299-310.

7. Li YL, Lin PJ, Tung KL. CFD analysis of fluid flow through a spacer-filled disk-type membrane module. Desalination 2011;283:140-147.

8. Mesquita M, Testezlaf R, Deus FP, Rosa LM. Characterization of flow lines generated by pressurized sand filter underdrains.
Chem. Eng. Trans. 2017;58:715-720.

9. Zhuang L, Guo H, Dai G, Xu Z. Effect of the inlet manifold on the performance of a hollow fiber membrane module-A CFD study. J. Membr. Sci. 2017;526:73-93.

10. Lipscomb GG, Sonalkar S. Source of non-ideal flow distribution and their effect on the performance of hollow fiber gas separation module. Sep. Purif. Rev. 2005;33:41-76.

11. Mat NC, Lou Y, Lipscomb GG. Hollow fiber membrane modules. Curr. Opin. Chem. Eng. 2014;4:18-24.

12. Yang X, Wang R, Fane AG, Tang CY, Wenten IG. Membrane module design and dynamic shear-induced techniques to enhance liquid separation by hollow fiber module: a review. Desalin. Water Treat. 2013;51:3604-3627.

13. Zhuang L, Guo H, Wang P, Dai G. Study on the flux distribution in a dead-end outside-in hollow fiber membrane module. $J$. Membr. Sci. 2015;495:372-383.

14. Wang L, Wang H, Li B, Wang Y, Wang S. Novel design of liquid distributors for VMD performance improvement based on cross-flow membrane module. Desalination 2014;336:80-86.

15. Oh JI, Choi JW, Lim JL, Kim DI, Park NS. A study on hydraulic modifications of low-pressure membrane inlet structure with CFD and PIV techniques. J. Kor. Soc. Environ. Eng. 2015;37: 607-618.

16. Versteeg HK, Malalasekera W. An introduction to computational fluid dynamics: The finite volume Method. 2nd ed. United Kingdom: Pearson Education Ltd.; 2007. p. 68-69.

17. Launder BE, Spalding DB. The numerical computation of turbulent flows. Comput. Methods Appl. Mech. Eng. 1974;3:269-289.

18. Dave C. Hollow fiber and tubular UF pilot testing procedures \& case studies [Internet]. CROWN Solutions Inc.: Veolia water [cited 18 April 2018]. Available from: http://www.veoliawatertech. com/crownsolutions/ressources/documents/2/21944. 